\title{
MACROPORES IN SNOWPACKS OF SIERRA NEVADA
}

by

\section{RichaRd KATteLMANN}

Central Sierra Snow Laboratory, Pacific Southwest Forest and Range Experiment Station, Forest Service, US Department of Agriculture, P.O. Box 66, Soda Springs, California 95728, USA

\section{ABSTRACT}

Macropores - large open channels that can conduct water - have been found within snowpacks of the Sierra Nevada of California. Extensive networks of channels as well as apparently isolated single channels have been documented. These openings, which are usually found near the base of the snowpack, were recognized at several widespread sites. Such basal channels may be an important means of draining liquid water from the snowpack. The presence of open conduits in snow helps to explain such phenomena as rapid streamflow response to percolating rain and melt water.

\section{INTRODUCTION}

Snow has generally been thought of as a porous medium somewhat analogous to coarse sand. Yet it can also route water through highly conductive flow pathways of larger-than-average grain size (Colbeck and others 1979). Principles of water flow through snow (Colbeck 1978) have been applied to prediction of runoff from a subarctic snowpack (Dunne and others 1976). The lag time between peak rates of snowmelt and runoff was slightly overestimated, possibly due to channeling of water underneath the snow cover (Colbeck 1978). The presence of conducting conduits in ice and soil suggests that such openings could also exist in snow.

Open channels within the snowpack but resting on the soil surface are recognized as an important means of routing meltwater to streams (Colbeck and others 1979). Open channels were found carved into and through basal ice layers of an arctic snowpack (Woo and others 1982), varying in diameter from a few millimeters up to a metre.

Open conduits are well known in glacial hydrology. In addition to the large tunnels found at the bed of glaciers, a network of passages may drain water through glacial ice. Many small channels drain the base of the firn layer. These small tributary channels successively join to form larger passages at greater depth until there is a relatively small number of large tunnels near the bed of the glacier (Shreve 1972; Meier 1973).

Macropores are also found in soils and appear to have considerable influence on soil water movement (Beven and Germann 1982). Depending on their location and structure, soil macropores can increase both infiltration and subsurface stormflow. Natural soil pipes are a type of macropore associated with subsurface erosion. This paper describes macropores observed in snowpacks of the Sierra Nevada of California and proposes some hypotheses about their development and hydrologic significance.

\section{MACROPORES IN SNOW}

Over the past several years, this author has opportunistically observed isolated openings within snowpacks in the forest zone of the northern Sierra Nevada and the alpine zone of the southern Sierra. Then, in early summer of 1983, large networks of openings were found as the snowpack melted (Figure 1). The principal study site was near the Forest Service's

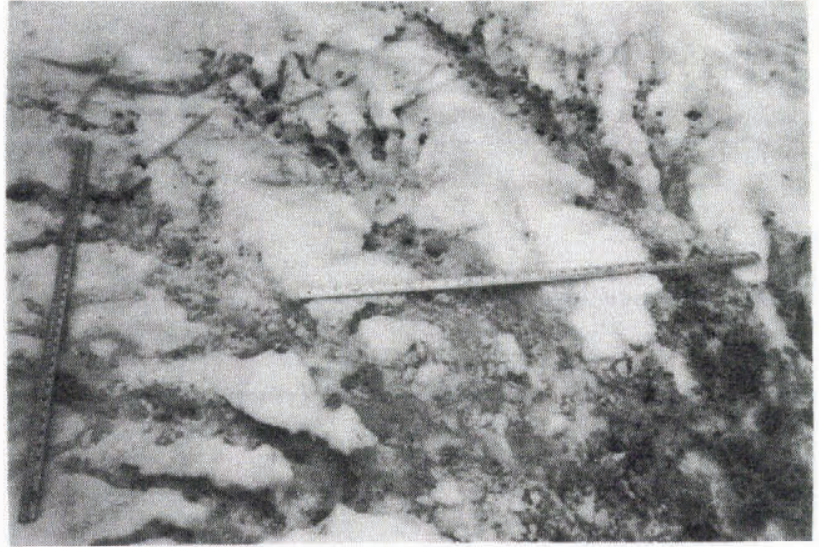

Fig.1. Networks of snow macropores can drain areas of several squares metres.

Central Sierra Snow Laboratory at Soda Springs, California. This area is just west of the Sierra Nevada crest at $2100 \mathrm{~m}$ elevation in the subalpine forest. Subject to a maritime influence, it accumulates deep seasonal snowpacks. The typical snowpack is isothermal most of the winter and has well-defined layers.

For observation, these openings are a very short lived phenomenon. They were visible for only one or two days between the time snowmelt uncovered them and then destroyed them. This brief exposure time may account for the lack of documentation. The macropores observed cover a wide range in sizes. They tended to be relatively constant in size for a particular height above the soil surface, regardless of snow depth. The smallest discernible openings were approximately $5 \mathrm{~mm}$ across. Small macropores tend to be circular in cross-section. When the diameter exceeds about $3 \mathrm{~cm}$, the cross-section becomes more oval with width exceeding height. This shape probably reflects the layered nature of snow. Most of the openings within networks were from 1 to $2 \mathrm{~cm}$ in diameter. Several of the larger openings had cross-sectional areas in excess of $100 \mathrm{~cm}^{2}$, and the largest cavity was about $1000 \mathrm{~cm}^{2}$. Isolated channels were traced for over $3 \mathrm{~m}$. In the networks, individual segments of a particular size were rarely more than one-half metre long, although total channel lengths of over $5 \mathrm{~m}$ were excavated.

All macropore networks were found in the lowest one-half metre of the snowpack on slopes of less than $10^{\circ}$. The largest channels of these networks existed near the base of the snowpack, of ten on a basal ice layer. The slope of these principal channels generally paralleled the slope of the snow layers. Smaller tributary channels were usually at steeper gradients than the main channels and often cut across snow layers. The isolated macropores were almost always found above or below a stratigraphic discontinuity in the snowpack such as an ice layer or layer boundary between snow of different grain sizes. 


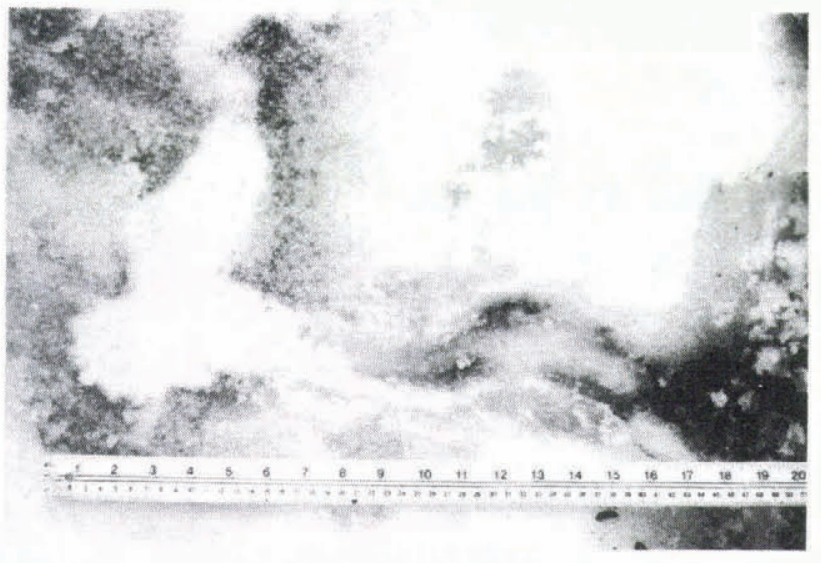

Fig.2. Plan view of a snow macropore (darker area in lower right half of photograph) originating in a zone of large cohesionless snow grains (white region at left).

\section{MACROPORE DEVELOPMENT}

The smallest macropores and a few of the larger ones originated in zones of above-average grain size (Figure 2). For a snow layer with an average grain diameter of $1 \mathrm{~mm}$, such zones consisted of grains about 2 $\mathrm{mm}$ in diameter and included a volume of a few dozen to a few hundred ccs. These zones were probably preferential water flow pathways. As grain size and pore size increase, these zones become more permeable and are capable of conducting more water. This process leads to additional grain growth. Some of these zones of large grains also contained soil particles when the surrounding snow did not, thus of fering additional evidence of water flow in these zones. Apparently, flowing water was in contact with the soil surface somewhere upslope. After exposing the beginning of several macropores, it was noticed that the degree of intergrain bonding appeared to diminish as the opening was approached. The grains nearest the opening lacked cohesion.

It is hypothesized that macropore networks in snow form during saturated conditions of excessive water flow in the basal snow layer. If there are preexisting flow pathways consisting of large grain snow, water would continue to concentrate in these zones of above-average permeability. If enough water enters the basal snow layer, the flowing water could exert sufficient shear stress on the weakly bonded grains to erode them and form an open channel. This erosion would start at an opening such as a stream channel and progress up-gradient. In snow, friction may provide enough heat to melt whatever bonds exist between the grains in the flow pathway. As the macropore network develops during saturated conditions, snowpack drainage should accelerate. As drainage increases, both the hydraulic head and the shear stress on the snow grains will decrease (assuming constant or declining water input), thus limiting the growth of the macropore network.

\section{HYDROLOGIC SIGNIFICANCE}

Snow macropores, both preexisting and in the process of formation, should substantially decrease the drainage time of a snow cover. Where macropores exist, streamflow response to an input of water at the snow surface should be much more rapid than in the absence of macropores. Flow in macropores will occur only when the surrounding snow is saturated - a situation analogous to an artificial tile drain. For water to flow in a macropore, the input of water must exceed the losses to the snow matrix, as in the case for soil macropores (Beven and Germann 1982).

In a snowpack without macropores, water may pond in the basal layers if water input exceeds the capability of the snow matrix to conduct water down slope. A macropore network is most likely to develop under these conditions. If open channels do form, the snowpack may suddenly release a large quantity of stored water. Such a release may cause a quick local rise in the receiving stream, perhaps long after water input at the snow surface has peaked. Flood peaks of this nature have been noted during and after rain-on-snow events.

\section{ACKNOWLEDGEMENT}

This research was partially supported by the Division of Atmospheric Resources Research, Bureau of Reclamation, US Department of the Interior.

\section{REFERENCES}

Beven K, Germann P 1982 Macropores and waterflow in soils. Water Resources Research 18(5): 1311-1325

Colbeck S C 1978 The physical aspects of water flow through snow. Advances in Hydroscience 11: 165-206

Colbeck S C, Anderson E A, Bissell V C, Crook A G, Male $D H$, Slaughter $C W$ and Wiesnet $D$, 1979 Snow accumulation, distribution, melt, and runoff. EOS, Transactions, American Geophysical Union 60(21): 465-468

Dunne T, Price A G, Colbeck S C 1976 Thegeneration of runoff from subarctic snowpacks. Water Resources Research 19(4): 971-978

Meier M F 1973 Hydraulics and hydrology of glaciers. In: The Role of Snow and Ice in Hydrology. Proceedings of the Banff Symposium. UNESCO-WMO-IAHS: 353-370

Shreve R L 1972 Movement of water in glaciers. Journal of Glaciology 11(62): 205-214

Woo M-K, Heron R, and Marsh P 1982 Basal ice in High Arctic snowpacks. Arctic and Alpine Research 14(3): $251-260$ 